\title{
Entrevistas com artistas: canteiro virgem de conteúdo fértil
}

\section{Resumo}

A partir da constatação de que se disseminou o uso de entrevistas em pesquisas no campo da História, Teoria e Crítica de Arte, o presente artigo procura advertir para os riscos de se incorrer em abordagens ingênuas e pouca fundamentadas, sobretudo no momento de análise do material produzido. Para tanto, estabelece uma premissa - a respeito do convívio, por vezes tensionado, entre obra e discurso do artista - e sugere dois caminhos de abordagem metodológica: a análise de conteúdo, proveniente das Ciências Sociais, e a História Oral. Por fim, aponta a necessidade de se problematizar a opção de publicações acadêmico-científicas e similares pela apresentação de entrevistas com artistas como gênero textual autônomo.

\section{Palavras-chave}

Entrevista. Entrevistas com artistas. Criação artística.

História Oral. Análise de conteúdo. 
1. Tradução de Sonia Salgado Labouriau, inédita em livro, para Another autointerview, de Lucas Samaras. 0 texto, publicado originalmente em Samaras Album: autointerview, autobiography, autopolaroid (Nova lorque: Whitney Museum of American Art and Place Edition, 1971), está disponível em STILES, Krstine; SELZ, Peter (orgs.). Theories and documents of contemporary art: a sourcebook of artist's writings. Berkley: University of California Press, 1996, p.349-355.
Depois de realizar uma extensa série de autorretratos em polaroide, Lucas Samaras (Kastoria, Grécia, 1936) dedicou-se a uma saborosa sequência de trabalhos não menos narcisistas: as suas autoentrevistas. Na mais célebre dessas investigações sobre si mesmo, em 1971, o autor abria a conversa propondo, insistentemente, uma mesma questão: "Por que você está fazendo esta entrevista?". As respostas, em contrapartida, saíam sempre distintas, oferecendo cada uma delas uma nuance particular:

Porque a entrevista é [...] um canteiro virgem de conteúdo fértil.

Por que você está fazendo esta entrevista?

Para que eu possa descobrir o que deixou de ser secreto.

Por que você está fazendo esta entrevista?

Para me proteger.

De quê?

Da imaginação das pessoas. [...]

Por que você está fazendo esta entrevista?

É uma forma de liberar culpa.

Por que você está fazendo esta entrevista?

Quero cristalizar a situação cotidiana de falar comigo mesmo.

Por que você está fazendo esta entrevista?

Para relaxar minha mente das obsessões do dia a dia.

Por que você está fazendo esta entrevista?

Para formalizar e isolar a mim mesmo.

Por que você está fazendo esta entrevista?

Para entrar na consciência dos outros. ${ }^{1}$

Quando Samaras pergunta a si próprio o porquê de tanta fé no discurso textual, ele mesmo responde: "As palavras evitam o esquecimento". As diferentes respostas formuladas em sequência pelo artista grego-norte-americano parecem extrapolar seu desejo de autoconhecimento. Acabam servindo como justificativas - amplas e sedutoras - para a realização de entrevistas com praticamente qualquer artista: porque esse tipo de conversação é canteiro 
virgem para conteúdo fértil, porque pode trazer à tona o que há de mais secreto, porque protege o entrevistado da imaginação dos outros, porque libera culpas, porque sistematiza a situação cotidiana de autorreflexão, porque relaxa a mente, porque permite entrar na consciência alheia. Enfim, porque esse gênero bastante singular de discurso - construído em turnos de fala, um perguntando, o outro respondendo, tudo costurado com um mínimo de objetividade - evita o esquecimento. Funciona, com sorte, como antídoto contra os apagamentos da memória.

Em diferentes campos de estudo ou em práticas cotidianas, tem sido largamente celebrado o potencial da entrevista como instrumento de construção de conhecimento. Sublinha Oliveira Bueno que o uso desse tipo de conversação na contemporaneidade decorre de "[...] uma longa história ligada a uma tradição filosófica e epistemológica que considera o discurso dialógico como produtor de saber e verdade."2 O mestre Jorge Luis Borges percorre a mesma vereda: "[...] os gregos começaram a conversar, e temos seguido desde então."3

No campo mais específico das artes visuais, que é o que nos interessa aqui, as entrevistas são comumente saudadas como "fonte de informação direta do artista."4 As conversações com artistas visuais são práticas mais ou menos correntes desde pelo menos a consolidação da modernidade. Ricardo Basbaum, ao enunciar a tese de que a arte moderna corresponderia a um "agenciamento particular" entre o visual e o verbal, chama atenção para a "proliferação de discursos" que passam a comentar as proposições de Courbet, Manet e seus contemporâneos: "[...] os homens do século XIX não se calam, não emudecem e iniciam a atividade, insistente e contínua, de falar e escrever a partir da imagem." Enumera o autor: aquele é o momento da eclosão não apenas da crítica de arte, mas também dos "textos teóricos, textos de artistas, crônicas, biografias, ensaios, manifestos e estudos de história da arte." ${ }^{5}$ Ele não chega a mencionar, mas bem poderia ter arrolado ali as entrevistas com artistas.

Um rápido exemplo: o biógrafo de Marcel Duchamp, Calvin Tomkins, detaIha o quanto o artista francês, ao se mudar para Nova Iorque, em 1915, foi tremendamente assediado por repórteres. Queriam saber o que ele tinha a dizer sobre a mulher americana ("a mais inteligente de todas", respondeu Duchamp), sobre a transferência já verificável do centro de difusão da arte moderna, da França para os Estados Unidos ("o país da arte do futuro", pontuou o rebelde da Alta Normandia) e sobre a guerra ("Pessoalmente, devo dizer que sou a favor de invasões de combate, mas de braços cruzados," ironizou). ${ }^{6}$

A motivação das entrevistas desde aquele momento, quase invariavelmente conduzidas por jornalistas, tinha a ver com a elaboração e fixação do que Edgar Morin identificaria como o novo Olimpo, onde os artistas encarnam os próprios olimpianos: seres que a cultura de massa alça à condição de
2. BUENO, Cleuza Maria de Oliveira. Entre-vista: espaço de construção subjetiva. Porto Alegre: Edipucrs, 2002, p.11-12.

3. BORGES, Jorge Luis; FERRARI, Osvaldo. En dialogo I. Buenos Aires: Sudamericana, 1998, p.25. [Tradução livre do autor]

4. FERREIRA, Glória. FÉLIX, Nelson. Trilogias - Conversas entre Nelson Félix e Glória Ferreira. Rio de Janeiro: Pinakotheke, 2005, p.7. [Grifo do autor]

5. BASBAUM, Ricardo. Além da pureza visual. Porto Alegre: Zouk, 2007, p.26-27.

6. TOMKINS, Calvin. Duchamp: uma biografia. São Paulo: Cosac Naify, 2004, p.171-175. 
7. MORIN, Edgar. Cultura de massa no século XX: 0 espírito do tempo. Rio de Janeiro: Forense Universitária, 1990.

8. TOMKINS, Opus cit., p.175.

9. FERREIRA, Opus cit., p.07.

10. KUH, Katharine. Diálogo com a arte moderna. Rio de Janeiro: Lidador, 1965, p.19.

11. STILES; SELZ, Opus cit., p.3-4. sobre-humanos, como astros e estrelas de cinema, campeões esportivos, políticos, escritores, músicos e também artistas visuais, sobretudo, pintores. ${ }^{7} \mathrm{~A}$ imprensa trata de apresentá-los de modo divinizante, ao mesmo tempo em que perscruta suas vidas privadas e suas impressões, em busca das essências mais mundanas, que estimulariam a identificação e os desejos dos leitores. Por outro lado, desde a cristalização do paradigma informativo do jornalismo, que vai se alimentar fundamentalmente de entrevistas, os artistas parecem perceber ali a possibilidade de valer-se dessas conversações para a divulgação de seus trabaIhos, sua imagem e suas ideias. 0 já citado Tomkins chega a se surpreender com a indiferença de Duchamp frente à insistente presença de repórteres em torno de si: "Se quisesse, Duchamp poderia ter certamente usado as entrevistas para promover sua carreira de artista."

Adiante, os anos 1950 conheceram um verdadeiro boom desse gênero de texto. Glória Ferreira relaciona a explosão tanto com o fenômeno da Pop Art e seu interesse na comunicação massiva (não por acaso chamava-se Interiew a revista concebida por Andy Warhol) quanto com o declínio, àquela altura, dos manifestos e dos programas artísticos das vanguardas históricas. Um formato ascendia à medida em que o outro se eclipsava. ${ }^{9}$

Ao lançar em 1965 seu The artist's voice, coletânea de entrevistas com 17 artistas então jovens ou no auge de sua produção, nascidos ou radicados nos Estados Unidos, Katherine Kuh aponta nas entrevistas a possibilidade de dar voz a quem menos fala:

Com o decorrer dos anos, os críticos e historiadores da arte têm estado ativos estudando o valor destes pintores e escultores, discutindo os seus trabalhos-chave, atribuindo-Ihes motivos, interpretando-os e "arrumando-os" em divisões. É justo que os artistas tenham uma oportunidade de responder, confirmando ou negando as alegações a seu respeito. ${ }^{10}$

Algo nessa linha é mencionado também por Kristine Stiles e Peter Selz. Afirmam os pesquisadores que a expansão "sem precedentes" das categorias tradicionais de pintura, escultura, gravura e desenho nas décadas de 1960 e 70 coincide com a adoção por arte dos artistas de uma variedade de práticas textuais, que vão incluir depoimentos e entrevistas, sobretudo em jornais e revistas editados por eles mesmos, artistas. Anota Stiles que, embora raramente se igualem em rigor aos textos críticos, as entrevistas teriam a notória vantagem de oferecer "acesso ao pensamento espontâneo", ausente nos "discursos teóricos autoconscientes."11

Mais recentemente, nos anos 1990, as entrevistas com artistas viriam preencher um vácuo, conforme a jornalista suíça Gabrielle Detterer. Os diálogos, nessa perspectiva, estariam em um ponto intermediário: entre os ensaios 
acadêmico-filosóficos de elevada erudição e as formas mais populares de comunicação - imediatistas e ligeiras. As entrevistas com artistas, sublinha Detterer, equivaleriam, antes, ao "desejo de uma comunicação transparente". Suas características indissociáveis seriam o hibridismo, a fragmentação, a autenticidade e o espírito polifuncional. Nas conversações, pondera a autora, o artista fornece tanto sofisticadas reflexões sobre estética e filosofia da arte quanto distrações e trivialidades: "Pensamentos precisos e miscelânea colidem. A simultaneidade da linguagem do dia a dia e o vocabulário da teoria da arte conectam mundos separados."12

Detterer aponta algo que, quase com as mesmas palavras, também aparece em Ferreira, Kuh ou Stiles: a entrevista surge como fonte direta de contato entre os artistas e o público, livre das intervenções interpretativas dos críticos. Haveria nessas conversações um "retorno ao artista como origem do discurso sobre a arte."13

Até aqui, neste artigo, revisei brevemente, cronologicamente, o que seria uma possível história das entrevistas com artistas, realçando características que, ao longo do século $X X$, se estabilizaram como muito próprias desse tipo tão singular de colóquio: sua condição de fonte mais direta ao pensamento dos artistas no comparativo com outras modalidades de textos, seu sentido promocional de carreiras e personalidades, sua sorte de acesso ao mais espontâneo e ao mais transparente, seu estatuto alternativo diante das interpretações por vezes tão imperiosas da crítica de arte. Haveria, porém, que ressaltar dois princípios que me parecem caros às entrevistas: um primeiro, mais geral, e um segundo, concernente de maneira específica aos diálogos com artistas. A saber:

(1) as ideias de um entrevistado quase nunca correspondem a máximas que já estejam prontas, uniformes e lapidadas, aguardando apenas a hora de serem enunciadas, dando voz a quem não a tem. Nos melhores casos, os pensamentos tomam forma, justamente, no contato com o outro, com aquele que se dispõe a perguntar e escutar;

(2) artistas, por mais bem-vindos que sejam na construção de discursos sobre suas obras, nem sempre têm clareza sobre o que fizeram. Convém não idealizar em demasia a potência do que dizem. Além disso, eles não correspondem, necessariamente, aos intérpretes mais autorizados ou mais competentes para avaliar a própria produção. Não faz sentido buscar o descortinamento de uma verdade única e inabalável em suas falas.

Caberia esclarecer ainda, a título de revisão bibliográfica, que o tema das entrevistas com artistas visuais, malgrado a disseminação de sua prática, não tem merecido grandes atenções no Brasil. Para além de prefácios e textos introdutórios em livros de entrevistas, são raríssimas as tentativas de problematização do que haveria de ímpar nessas conversas. Contamos com as estimulantes
12. DETTERER, Gabriele (org.). Art recollection - Artists' interviews and statements in the Ninethies. Ravena: Danilo Montanari / Exit / Zona Archives Editori, 1997, p.12. 13. Idem, ibidem, p.12. [grifos do autor]. 
14. SANTHIAGO, Ricardo. História Oral e as artes: percursos, possibilidades e desafios. In: História Oral, v. 16, n. 1, jan./jun. 2013, p.168.

15. A partir de três estudos de caso, examinando trabalhos de Anico Herskovits, Jailton Moreira e Maria Helena Bernardes, eu realizava entrevistas com esses artistas e discutia a natureza e as possibilidades de leitura sugeridas pelas conversações. Mantinha como principal eixo teórico-disciplinar os estudos sobre documentos de trabalho, conforme acepções da chamada Crítica Genética. Ver VERAS, Eduardo. Entre ver e enunciar - O uso da entrevista em estudos sobre 0 processo de criação artística. Programa de Pós-Graduação em Artes Visuais. Universidade Federal do Rio Grande do Sul. Dissertação (Mestrado). Porto Alegre, 2006. Adiante, publiquei um dos capítulos: VERAS, Eduardo. Diante do enigma. In: ASSIS BRASIL, Luiz Antonio de (coord.); DOVAL, Camila Canali; SILVA, Camila Gonzatto da; SILVA, Gabriela (orgs.). A escrita criativa Pensar e escrever literatura. Porto Alegre: Edipucrs, 2012, p.138-157. Mais recentemente, retomei essas questões em VERAS, Eduardo. História Oral e História da Arte: aproximações. In: SANTHIAGO, Ricardo (org.). História oral e arte: narração e criatividade. São Paulo: Letra e Voz, 2016, p.137-162, e em uma comunicação no XXXVI Colóquio do Comitê Brasileiro de História da Arte, Salvador, 2017, ainda inédita como texto.

16. Laboratório de Pesquisa em História da Arte III é uma disciplina obrigatória (60 horas), voltada à pesquisa com entrevistas. Está prevista para a $6^{a}$ etapa na grade curricular do Bacharelado em História da Arte. 0 tópico especial Entrevistas com Artistas: Usos, Especificidades e Métodos, de caráter eletivo, foi oferecido por mim para turmas de Mestrado e Doutorado do PPGAV/UFRGS em 2013 e 2017.

17. Obrist discute os conceitos de zona de performance e maratona de entrevistas em uma entrevista para Marcelo Rezende, em OBRIST, Hans Ulrich. Arte agora!: em cinco entrevistas. São Paulo: Alameda, 2006, p.99-114. reflexões do historiador e comunicólogo Ricardo Santhiago, que examinam fontes orais e arte de modo mais geral (e não especificamente de artes visuais) e que tratam a questão desde outro campo de observação: diferentemente de mim, ele compreende a História Oral como um campo de conhecimento, já consolidado e institucionalizado, e não como uma metodologia. Santhiago se pergunta por que a História Oral dedica tão pouca atenção à criação artística, quando teria tanto a contribuir. ${ }^{14}$ É um dos pontos em que nossas abordagens convergem: feito ele, acredito que a História Oral nos ofereça instrumentos conceituais e teóricos muito potentes, sobretudo para a análise dos depoimentos recolhidos (a meu ver, uma metodologia, disponível entre outras, para aplicação no campo de estudos em que me movimento: o da História da Arte ou, mais amplamente, o da História, Teoria e Crítica de Arte). Partilhamos também, Santhiago e eu, da noção de que, antes da fixação de um sistema ou uma técnica ideal, caberia uma abertura às ambições multifocais das pesquisas e ao exercício efetivo da transdisciplinaridade. Essas duas questões serão retomadas adiante, no desenvolvimento deste artigo.

Chego, por fim, ao momento em que não gostaria de parecer cabotino ou excessivamente vaidoso, mas serei obrigado a citar minha própria dissertação de Mestrado e seus desdobramentos como se fossem textos referenciais. 0 trabalho, defendido em 2006, discutia o uso e as particularidades do uso de entrevistas com artistas em estudos sobre o processo de criação. ${ }^{15}$ Como eu vinha de uma experiência de mais de dez anos na prática do jornalismo diário, dedicado sobretudo a realizar entrevistas com artistas, me intrigava o fato de que, na academia, e tão amiúde, se optasse por uma naturalização dessas conversas, raramente se explicitando que havia, sim, uma metodologia em curso e que seu emprego deveria ser problematizado.

0 presente artigo retoma questões que eram discutidas ali, procurando atualizadas à luz do debate recente com Ricardo Santhiago e de minha própria experiência como professor no Instituto de Artes da UFRGS, ministrando, na Graduação e na Pós-Graduação, disciplinas específicas sobre entrevistas com artistas e acompanhando as pesquisas dos alunos. ${ }^{16}$

Meu foco específico neste artigo - finalmente anuncio - são as entrevistas com artistas em contexto acadêmico. Não discutirei, por mais interessantes que sejam, proposições como as do curador suíço Hans Ulrich Obrist, que pensa nas entrevistas como zonas de performance, que podem assumir o formato de maratonas de conversação e que costumam dar origem a livros ou projetos curatoriais. ${ }^{17}$ Tampouco vou abordar os artistas que recorrem a entrevistas ou autoentrevistas na configuração de seus trabalhos, como o britânico Michael Craig-Martin ${ }^{18}$ ou o já citado Lucas Samaras. Manterei presente, porém, a noção de que a entrevista pode funcionar como canteiro virgem de conteúdo fértil. 


\section{II}

Nos meios acadêmicos, no Brasil e no exterior, as entrevistas com artistas talvez não correspondam ainda a uma febre ou um modismo, mas, de qualquer forma, encontram-se largamente disseminadas na composição de narrativas textuais e outros modos de discurso: os diálogos, sobretudo quando se dão em torno de processos de criação e motivações dos autores, aparecem como instrumento deveras afinado para a geração de conhecimento. A título de exemplo, ainda que brevemente, talvez bastasse examinar as produções intelectuais provenientes do Bacharelado em História da Arte da UFRGS e de seu correlato no Programa de Pós-Graduação em Artes da mesma instituição: a ênfase em História, Teoria e Crítica de Arte. ${ }^{19}$ Das 34 teses de doutorado defendidas ali desde a formação da primeira turma, em 2005, 18 recorrem a entrevistas. ${ }^{20}$ Isso equivale a mais da metade. Entre as dissertações, no mesmo período, de 2005 a 2017, os números são ainda mais impressionantes. Dos 63 novos mestres da ênfase em História, Teoria e Crítica de Arte, 38 lançam mão de entrevistas, ou seja, mais de $60 \%$ do total. ${ }^{21}$ No bacharelado em História da Arte, considerando-se desde a primeira turma de formandos, de 2013 , até a mais recente, em 2016, há um total de 19 novos bacharéis, sendo que dez deles se valem de entrevistas em suas monografias finais. ${ }^{22}$

Se os números chamam atenção pela quantidade de trabalhos acadêmicos que contam com entrevistas entre suas fontes documentais, o levantamento é capaz de revelar dados ainda mais surpreendentes. Poucos desses pesquisadores chegam a submeter a algum tipo de análise sistematizada as falas que ajudam a configurar. Das 18 teses que abraçam entrevistas entre suas fontes, apenas quatro assumem o emprego de algum tipo de análise crítica do material. Das 38 dissertações com entrevistas, apenas seis declaram que os depoimentos são submetidos a algum tratamento. No caso dos 10 TCCs, um único anuncia essa disposição reflexiva. É possível, sem dúvida, que, mesmo sem explicitar, os pesquisadores da Graduação e da Pós tenham sujeitado as fontes orais a algum tipo de juízo. Provavelmente não o fizeram. Ou pelo menos não tiveram consciência de fazê-lo.

Disso, pode resultar, certa fragilidade metodológica, certa ausência de rigor. Corre-se o risco de tratar de forma ingênua os depoimentos recolhidos e, ao mesmo tempo, desperdiçar as nuances presentes nas falas, as seleções típicas das narrações memorialísticas, seus inevitáveis esquecimentos. Daí porque, muito frequentemente, ao desdenhar de uma análise mais sistematizada, termina-se por alcançar interpretações menos vigorosas. A qualidade dos trabalhos como um todo tende a ficar comprometida.

Feito esse alerta, chego ao cerne desta comunicação: a sugestão de pelo menos dois diferentes modelos interpretativos, que ajudariam a evitar essas debilidades no tratamento das entrevistas. Antes de passar a eles, porém, eu
18. Na instalação Um carvalho, apresentada pela primeira vez em 1973, Craig-Martin inclui na parede, junto a um copo d'água, uma autoentrevista em que narra e discute como transformou aquele objeto em uma árvore.

19. Escolho esses cursos, nos quais leciono, não apenas em razão da proximidade, mas antes pelo fato de as teses e dissertações defendidas a partir de 2005 estarem disponíveis no site do programa: https://www.ufrgs.br/ ppgav/defesas/\#page. 0 mesmo se dá com os TCCs do Bacharelado em História da Arte da UFRGS, disponíveis no Lume: http://www. lume.ufrgs.br/handle/10183/15757. 20. No mesmo período, no mesmo programa, foram defendidas 57 teses de doutorado em Poéticas Visuais. Embora três delas contassem com entrevistas entre as fontes submetidas a exame, elas não serão somadas aqui, porque nossa discussão restringe-se a trabalhos em História, Teoria e Crítica de Arte.

21. No mesmo período, no mesmo programa, foram defendidas 114 dissertações em Poéticas Visuais, sendo que seis delas recorriam a entrevistas. Não serão computadas aqui porque essa análise se ocupa apenas de estudos em História, Teoria e Crítica de Arte.

22. Nos três casos citados (teses, dissertações e TCCs), as entrevistas não se restringem a artistas. Entre os interlocutores eleitos por doutorandos, mestrandos e bacharelandos de História da Arte na UFRGS, figuram curadores, críticos de arte, marchands, colecionadores, jornalistas especializados, familiares de artistas, ex-alunos de artistas professores, gerentes de espaços públicos e privados, e, por fim, habitués de vernissages. 
23. Esses debates, que acompanham a História da Arte desde a Antiguidade e alcançam nossa era, são muito resumidamente abordados em minha dissertação: VERAS, Opus cit, p.29-30. Trechos dos textos originais que alimentaram 0 debate do paragone e do Laocoonte estão disponíveis em LICHTENSTEIN, Jacqueline (org.). A pintura: textos essenciais. Vol. 7: 0 paralelo das artes. São Paulo: Editora 34, 2005. Ver também GREENBERG, Clement. Rumo a um mais novo Laocoonte. In: FERREIRA, Glória; COTRIM, Cecilia (orgs.). Clement Greenberg e o debate crítico. Rio de Janeiro: Jorge Zahar Editor, 1997, p.45-59.

24. Pós-conceitual é um conceito formulado pelo historiador da arte Alexander Alberro para identificar certa contemporânea, fortemente decalcada na discursividade e nos seus contextos de instauração. Ver ALBERRO, Alexander; BUCHMANN, Sabeth (orgs.). Art after conceptual art. Cambridge / Londres / Viena: The MIT Press / Generali Foundation, 2006.

25. BOURGEOIS, Louise. Destruição do pai / Reconstrução do pai. São Paulo, Cosac Naify, 2000, p.66.

26. VERAS. Opus cit., p.12.

27. ECO, Umberto. Apostillas a EI nombre de la rosa. Buenos Aires: Lumen / Flor, 1987, p.14, minha tradução. proporia a adoção de uma premissa, também ela potencialmente alentadora.

Recomendo que nas diferentes fases das conversações com artistas, do preparo à realização em si e, por fim, no momento de examinar o material, o pesquisador mantenha presente a noção da existência de distâncias, diferenças e tensões entre a imagem e a palavra, entre o verbal e o visual. Não digo que seja imprescindível revisar, a cada entrevista realizada, antigos (e por vezes apaixonantes) debates como o Ut pictura poesis erit, o paragone ou o Laocoonte ${ }^{23}$, mas haveria que manter viva a advertência que eles nos fazem: exceção feita a certos fascinantes trabalhos de arte conceitual ou pós-conceitual ${ }^{24}$, obra e texto quase nunca são a mesma coisa.

Talvez ainda mais adequado fosse enfatizar um desdobramento desse ponto, aquele que diz respeito ao convívio, nem sempre harmonioso, entre a criação artística propriamente dita e os discursos sobre ela, sobretudo os provenientes dos artistas mesmos, sejam descrições, relatos sobre intenções ou até sugestões interpretativas. Seguidamente os próprios artistas vêm nos alertar para a inconveniência de se confundir essas instâncias, em geral bastante diversas.

\section{Comenta Louise Bourgeois:}

As palavras de um artista precisam ser interpretadas sempre com cuidado. A obra concluída é com frequência estranha, e às vezes representa o contrário daquilo que o artista sentiu ou quis expressar quando começou. No melhor dos casos, o artista faz o que pode em vez do que quer. Passada a batalha e encarados os estragos, o resultado pode ser surpreendentemente tedioso - porém, às vezes, é surpreendentemente interessante. [...] 0 artista que discute o tal sentido oculto do seu trabalho normalmente está descrevendo um assunto literário e secundário. 0 cerne do seu impulso original está, se estiver, no trabalho em si. ${ }^{25}$

Waltercio Caldas, na mesma linha:

Se me coloco como advogado do meu trabalho, tenho que advogar o fato de que ele está sendo minimizado nesta situação [de uma entrevista] e que a minha pessoa e o meu depoimento estão sendo mais valorizados do que a visão do meu trabalho. Como acho que é na experiência de ver o trabalho, de estar diante do trabalho, que tudo se justifica, é importante que se mantenha esse parâmetro. ${ }^{26}$

Umberto Eco, antes como romancista do que como semiólogo e ensaísta:

Ali está o texto [a obra de arte], que produz seus próprios efeitos de sentido, Independentemente de minha vontade [como autor], a pergunta se coloca, aparece a ambiguidade[...]. 0 autor deveria matar-se depois de ter escrito a obra. Para suavizar o caminho para o texto. ${ }^{27}$

Ocorre que os mesmos artistas/autores, passado algum tempo, assentadas as emoções da criação, tendem a modular suas restrições, à primeira vista 
tão severas. De alguma forma, aludem a outras possibilidades de enunciação e leitura daquilo que teriam a dizer. Bourgeois: "O artista deve dizer o que sente. O meu trabalho cresce do embate entre o indivíduo isolado e a consciência compartilhada do grupo."28 Waltercio: "Posso falar sobre um assunto que me interessa ou sobre o assunto que gera minhas preocupações." ${ }^{29}$ Eco: "O autor não deve interpretar. Mas pode contar como e por que escreveu." ${ }^{30}$

Malgrado as imperfeições ou as contradições do discurso, com sorte porque elas existem, os depoimentos dos artistas/autores - ao serem examinados com acuidade - podem ser estimulantes e desafiadores. Essa premissa, mais do que uma chave mágica para fabulações hermenêuticas, funcionaria como uma espécie de alerta: que os depoimentos sobre a criação não sejam literários e secundários, como enfatiza Bourgeois, mas que cresçam na consciência compartilhada com seus interlocutores. Com algum amparo metodológico, eles ajudarão a depurar o processo em que a história da arte, a crítica de arte, os diferentes intérpretes e o púbico em geral extraem o açúcar do melaço.

\section{III}

Nas disciplinas que tenho ministrado sobre usos, especificidades e metodologia de entrevistas no campo da arte, seja no Bacharelado em História da Arte ou na Pós-Graduação em Artes Visuais, proponho, logo depois de discutir as tensões entre obra e discurso sobre a obra, que se empreenda a um exame de conceitos, fundamentos e disposições técnicas da análise de conteúdo, metodologia cara às Ciências Sociais, e da História Oral. Certamente outras possibilidades haveria, como, por exemplo, a análise de discurso, proveniente da Linguística. Acredito, porém, que a análise de conteúdo e a História Oral, bem compreendidas e bem empregadas, já ofereçam princípios suficientemente sólidos para estudos criteriosos em História da Arte. As duas vertentes trabalham com a noção de que o pesquisador precisa manter alerta a consciência do caráter subjetivo, relacional, provisório e circunstancial das entrevistas. A entrevista emerge daí como um texto tramado a dois, em um contexto particular, segundo interesses em vigência naquele determinado momento.

Algum cotejo, ainda que breve, entre a prática jornalística e a pesquisa acadêmica, há de esclarecer melhor a importância da aplicação metodológica. $O$ cientista da área das Humanidades, diferentemente do profissional da imprensa, não pode permitir-se o luxo da inconsciência. Compara Jean-Pierre Rioux: o jornalista "[...] recolhe material de qualquer jeito e inventa fontes sem poder tratá-las." ${ }^{31}$

Na realização da entrevista, um jornalista está autorizado - pela própria prática e pelas convenções do campo - a pressionar, interromper e induzir o

\author{
28. BOURGEOIS, Opus cit, p.66. \\ 29. VERAS, Opus cit., p.12. \\ 30. ECO, Opus cit, p.15.
}

31. RIOUX, Jean-Pierre Entre História e Jornalismo. In: CHAUVEAU, Agnès; TETART, Phillipe (orgs.) Questões para a História do Presente. Bauru: Edusc, 1999, p.121. 
32. SHERWOOD, Hugh C. A entrevista jornalística. São Paulo: Mosaico, 1981, p.79.

33. BLANCHET, Alain; GOTMANN, Anne. L'enquête et ses méthodes: l'entretien. Paris: Nathan, 1992, p.67. [tradução livre do autor]
34. CRIPA, Marcos (org.). Entrevista e ética: uma introdução. São Paulo: Edusc, 1998, p.16.

35. Idem, ibidem, p.95. 36. Idem, ibidem, p.92.

37. CONTI, Mario Sergio. Memórias do presente. Publicado originalmente no site nominimo. Hoje, disponivel em http://www. observatoriodaimprensa.com.br/ artigos/asp170620035.htm. Acesso em 20/09/2017. entrevistado. Pondera Hugh Sherwood que a entrevista precisa ser "produtiva"; para tanto, segundo o repórter e professor de Jornalismo estadunidense, é lícito forçar uma declaração "fundamentada". ${ }^{32} \mathrm{Na}$ transcrição da entrevista, tem-se não apenas como legítimo mas como recomendável corrigir cacoetes de fala e redundâncias próprias da expressão oral. Na edição do material, para efeitos de comunicabilidade ou em nome de um melhor fluxo narrativo, altera-se a ordem das perguntas e das respostas. Trechos inteiros desaparecerem.

Em diferentes campos das Ciências Humanas, em contraponto, recomendase consensualmente ao entrevistador que cultive a paciência e a tolerância, que evite mostrar-se esperto e perspicaz. Em princípios dos anos 1940, as Ciências Sociais - em especial, Roethlisberger e Dickson - fixaram princípios que ainda hoje norteiam o uso de conversações para fins de pesquisa: o entrevistador, ainda que seja "inteligentemente crítico", não deve aconselhar o entrevistado, nem julgá -lo, tampouco discutir com ele. ${ }^{33}$ Manuais de Sociologia e História Oral parecem de acordo quanto ao que se deva, em qualquer caso, esperar daquele que conduz o diálogo: a criação de um clima de solidariedade profissional, ao mesmo tempo sincero e fraterno; a atenção em relação à fala do depoente; a permissão para deixar fluírem as lembranças sem maiores interrupções; o acolhimento a eventuais delírios digressivos; a recondução sempre cuidadosa aos temas da pesquisa; jamais gravar a fala do outro sem anuência prévia. Na transcrição, preservar, mais do que a literalidade, os sentidos originais do que lhe foi confiado.

$\mathrm{Na}$ comparação com o jornalismo, distâncias ainda maiores se estendem quando se considera a percepção corrente sobre as razões de ser da entrevista. Jornalistas, em geral, buscam a verdade como algo que aconteceu. Os muito conscienciosos acreditam que chegarão a ela a partir de uma apuração bem feita, da inquirição minuciosa das fontes, da checagem obsessiva dos detalhes, do cruzamento exaustivo de diferentes versões. A verdade, aqui, dificilmente será compreendida como representação dos acontecimentos, representação - parcial e provisória - que o entrevistado faz do mundo ou de si mesmo. A ilusão do repórter é, na maioria dos casos, alcançar os fatos e não uma imagem deles. 0 entrevistado surge como alguém capaz de descortinar algo concreto, real, objetivo. Armando Nogueira dizia que a entrevista tenta "extrair a verdade." ${ }^{34}$ Boris Casoy compara o jornalista a um saca-rolha: alguém que deve "trazer a informação à tona." ${ }^{35}$ Ricardo Kostcho equipara a entrevista a um namoro: "O entrevistado tem que ser conquistado para dizer aquilo que você quer saber."36 Mario Sergio Conti adverte para necessidade de o repórter "[...] saber tirar dele [o entrevistado] o que ele tem de melhor."37 Tirar, conquistar, trazer à tona, extrair. Haveria algo que o entrevistado possui e que ao entrevistador interessa tornar público.

0 atual desenvolvimento teórico das Humanidades não autoriza esse tipo de busca pela verdade factual sem a incorporação das elaborações feitas pelos 
sujeitos. Em seu Manual de História Oral, Sebe Bom Mehy menciona a impossibilidade de se resgatar memória. A memória, anota ele, não é algo concreto que se possa libertar:

[...] o que se diz [sobre os depoimentos orais] é que comumente são inexatos, cheios de interferências emocionais e vieses variados. Ao contrário do que se pensa, é exatamente o conjunto dessas alterações que interessa. Ademais, mora na emoção e mesmo na paixão de quem narra a subjetividade que interessa à história oral. ${ }^{38}$

\section{IV}

Embora alguns entusiastas da História Oral refiram-se a ela como uma disciplina ou um campo de conhecimento, a própria Associação Brasileira de História Oral enfatiza suas características de metodologia de pesquisa, ou seja, algo que estabelece e ordena procedimentos de trabalho. ${ }^{39}$ Suas origens remontam ao pós-guerra, coincidindo com a propagação de bons equipamentos de gravação nos Estados Unidos e na Europa e, ao mesmo tempo, com o desejo de sistematização de depoimentos sobre a experiência da II Guerra Mundial. Allan Nevins montou os primeiros arquivos e cunhou o termo História Oral em 1948, na Universidade de Columbia, em Nova Iorque. A inspiração mais direta vinha da Escola de Sociologia de Chicago, onde havia já 30 anos recolhiam-se depoimentos na forma de histórias de vida. No primeiro momento, os entrevistados eram figuras ilustres, mas, a partir dos anos 1950, dezenas de associações e universidades estadunidenses para a ouvir, além das elites, a gente comum. Na década seguinte, a chamada nova esquerda da historiografia britânica, no espírito da contracultura, compreendeu a História Oral como "uma contra-história", ou "uma história vista de baixo", escolhendo seus depoentes, de preferência, entre "os silenciados nos registros oficiais." ${ }^{40}$ No Brasil, a consolidação se deu nos anos 1970, graças à Fundação Getúlio Vargas, no Rio, até hoje o centro maior de referência na sistematização de fontes orais no país.

Em termos teóricos, a prática da História Oral busca amparo em autores que se dedicam a discutir e a problematizar o universo das lembranças (as individuais e as coletivas), os processos de rememoração dos acontecimentos e os diferentes modos de atualização do passado no presente - caso das formulações de David Lowenthal, Maurice Halbwachs e Michael Pollak, entre outros. A metodologia considera também os riscos daquilo que Pierre Bourdieu chamou de ilusão biográfica. Segundo o sociólogo francês, quando se pede a alguém que exponha uma experiência ou que conte a própria vida, o relato "[...] se baseia sempre, ou pelo menos em parte, na preocupação de dar sentido, de tornar razoável, de extrair uma lógica ao mesmo tempo retrospectiva e
38. MEHY, José Carlos Sebe Bom. Manual de História Oral. São Paulo: Loyola, 2002, p.47.

39. Criada em abril de 1994, no Rio de Janeiro, a Associação Brasileira de História Oral (ABHO) promove encontros nacionais de pesquisa a cada dois anos e publica regularmente uma revista científica. No site oficial, apresenta seus propósitos: http://www. historiaoral.org.br/.

40. MEHY, Opus cit, p.88-99. 
41. BOURDIEU, Pierre. "A ilusão biográfica". In: AMADO, Janaína; FERREIRA, Marieta de Moraes Ferreira (orgs.). Usos \& abusos da História Oral. Rio de Janeiro: Fundação Getúlio Vargas, 1996, p.184.

42. PORTELLI, Alessandro. "O que faz a história oral diferente". In: Revista do Programa de PósGraduados em História e do Departamento de História - PUC SP. Projeto História, São Paulo, n. 14, fev. 1997, p.33.

43. Idem, ibidem, p.31.
44. Não haveria tempo e espaço aqui para uma apresentação mais detalhada da análise de conteúdo. Autores referenciais sobre essa metodologia são Grawitz, Krippendorff, Mucchielli, Olabuenaga, Ispizua e F. Rosemberg. Uma boa síntese, incluindo um passo a passo para sua aplicação, está disponível em MORAES, Roque. "Análise de conteúdo". In. Revista Educação. Porto Alegre, v. 22, n. 37, p.7-32, 1999.

45. Idem, ibidem.

46. Idem, ibidem. prospectiva, uma consistência e uma constância." ${ }^{41} \mathrm{Na}$ síntese de Alessandro Portelli, a memória, tal qual ela costuma ser compreendida pela História Oral, não se restringe a "[...] um depositário passivo de fatos", sendo antes "[...] um processo ativo de significações." 420 crítico literário italiano, uma das maiores referências internacionais no uso de História Oral, enfatiza a sorte de nuances que o pesquisador há que perceber nas narrativas: "Fontes orais contamnos não apenas o que o povo fez, mas o que queria fazer, o que acreditava estar fazendo e o que agora pensa que fez." ${ }^{43}$

Sublinhe-se, por fim, que não há nessa metodologia uma fórmula mágica que nos vacine contra as incertezas e os equívocos interpretativos. No momento de analisar o material disponível, a História Oral não prevê um esquema rígido, com etapas a serem processadas; no máximo, nos adverte para que se cumpram os procedimentos digamos já clássicos de crítica da fonte caros à História como disciplina: a entrevista, a exemplo de outros documentos, (1) deve ser examinada em termos de sua coerência interna e seu contexto de aparição, (2) precisa ser cotejada com outras fontes (não necessariamente em busca do que seria uma possível verdade dos fatos, mas quem sabe justamente a tentativa de valorização ou entendimento de suas potências ficcionais) e (3) deve, por fim, ser observada em um quadro histórico-contextual amplo - nunca isolada.

Àqueles que não abrem mão de metodologias mais ortodoxas e seguras, uma alternativa eficaz seria a escolha pela análise de conteúdo. Amplamente adotada no campo das Ciências Sociais desde o final do século XIX, a análise de conteúdo descreve e interpreta um sem-número de documentos. Grosso modo, pode ser apresentada, no caso de entrevistas, como uma abordagem crítica da fala dos depoentes a partir da fragmentação dos discursos em unidades de análise (de registro ou significado) e de sua categorização, por semelhança ou analogia, em um processo de classificação que pareça, a uma só feita, consistente e estimulante.

Esse tratamento, tanto quantitativo quanto qualitativo, busca uma compreensão dos significados explícitos ou apenas latentes em um nível além daquele presente em uma leitura mais rápida. ${ }^{44}$ Observa Roque Moraes que tal metodologia se desenvolve de forma cíclica e circular, nunca sequencial e linear: "Os dados não falam por si. É necessário extrair deles o significado."45 Acrescenta o pesquisador que isso dificilmente se atinge em um único esforço: "O retorno periódico aos dados, o refinamento progressivo das categorias, dentro da procura de significados cada vez melhor explicitados, constituem um processo nunca verdadeiramente concluído, em que a cada ciclo podem atingir-se novas camadas de compreensão."46 Autores menos entusiasmados, ao revisar essa metodologia, vão ressaltar que sua eficácia dependerá sempre da 
experiência do pesquisador, seja na realização ou na análise das entrevistas. ${ }^{47}$ Exemplo notável de boa aplicação de análise de conteúdo no campo da História, Teoria e Crítica de Arte é a dissertação de Mestrado de Luísa Martins Waetge Kiefer. Em sua abordagem do processo histórico e social de construção do que seria o "jovem artista" na contemporaneidade, ela obteve resposta de 50 artistas, crítico e curadores via questionário, e realizou entrevistas em profundidade, de tipo semiestruturado, com seis jovens artistas. As categorias da análise de conteúdo acabaram estruturando a parte mais interpretativa da dissertação. ${ }^{48}$

0 que procurei enfatizar neste artigo foi a necessidade de certos cuidados a serem tomados pelo pesquisador, menos da preparação ou na condução das entrevistas com artistas, mas sobretudo na interpretação do material produzido. As entrevistas, mal ou bem se realizam. Como bem observa Consuelo Lins, não há um manual das perguntas corretas ou do caminho infalível para a melhor realização de uma conversa desse tipo: "A cada vez que acontece uma entrevista, surgem resoluções diferentes, com seus erros e acertos." ${ }^{49}$ Acrescenta Eduardo Coutinho, documentarista amplamente saudado como entrevistador exemplar, que, na hora da entrevista, boa parte do que ocorre tem a ver, inevitavelmente, com acaso e improviso: "Você pergunta e depois se arrepende. Ou não pergunta e deveria ter perguntado. Ou faz uma pergunta imbecil." ${ }^{50} \mathrm{O}$ material nunca estará perfeito. Guardo, porém, a convicção de que certos conceitos, certas referências teóricas e certo apuro metodológico - provenientes da História, das Ciências Sociais ou ainda de outros campos de conhecimento - tendem a nos encaminhar, a posteriori, a um aproveitamento mais consequente das fontes construídas em diálogo, com resultados mais densos e mais estimulantes.

Não foi meu objetivo, aqui, fixar um modelo único ou ideal para o tratamento crítico das fontes orais, tampouco a formulação de uma História Oral da Arte. Bem antes, reafirmo a crença em uma metodologia em constante construção, dependente da combinação e recombinação de diferentes referências, advindas de distintas disciplinas, em uma perspectiva multifocal; com sorte, sobrepondo-se às tradições fronteiras de campos estanques de conhecimento. Como sugere Francis Ponge, um método que se faz vai-que-vai, muito pouco a cada dia: "Uma coisinha de nada, mas com estilo." ${ }^{11}$

$\mathbf{V}$

Seria preciso incluir um derradeiro tópico nessa reflexão sobre usos e especificidades das entrevistas com artistas no campo disciplinar da História, da Teoria e da Crítica de Arte. Trata-se de uma questão bem recente e, até onde percebo, ainda não discutida ou nem sequer identificada, aguardando uma incontornável
47. O tema é discutido por autores como Rocha e Deusdará, Campos e Turato, e Nehmey. Uma revisão dessas críticas está disponível em CAVALCANTE, Ricardo Bezerra; CALIXTO, Pedro; PINHEIRO, Marta Macedo Kerr. Análise de conteúdo: considerações gerais, relações com a pergunta de pesquisa, possibilidades e limitações do método. In: Inf. \& Soc. João Pessoa, v. 24, n. 1, p.13-18, jan./ abr. 2014.

48. KIEFER, Luísa Martins Waetge. Jovem artista: a construção de um duplo mito. Programa de Pós-Graduação em Artes Visuais. Universidade Federal do Rio Grande do Sul. Dissertação (Mestrado). Porto Alegre, 2013. Verificar em especial o capítulo 4, "O jovem artista a partir do jovem artista", p.79-123.

49. LINS, Consuelo. 0 documentário de Eduardo Coutinho. Rio de Janeiro: Jorge Zahar, 2004, p.146.

50. VERAS, Eduardo. Enfim, uma pessoa interessante. In: Cultura. Zero Hora. Porto Alegre, 4 fev. 2006, p.6-7.

51. PONGE, Francis. Métodos. Rio de Janeiro: Imago, 1997, p.27. 
52. FERREIRA, Glória. Entrefalas. Porto Alegre: Zouk, 2011, p.7. A autora, obviamente, não considera aqui 0 fato de que mesmo essas entrevistas realizadas por ela poderão ser submetidas, adiante, a avaliações e tratamentos críticos por parte de diferentes autores, ligados ou não à academia. Reitera, desse modo, a acepção da entrevista como um gênero autônomo de texto.

53. Idem, ibidem, p.165.

54. SCOVINO, Felipe. Arquivo contemporâneo. Rio de Janeiro: 7 Letras, 2009 , p.7.

55. Idem, ibidem, p.10.

56. Idem, ibidem, p.14.

57. CHIARELLI, Tadeu. No calor da hora - Dossiê jovens artistas paulistanos (década de 1980). Belo Horizonte: C/Arte, 2011, p.20. problematização: de forma crescente, entrevistas com artistas têm sido apresentadas como um gênero autônomo de texto em publicações acadêmico-científicas - ou em publicações muito próximas a elas. Poderíamos considerar aqui o próprio dossiê desta edição da Revista Porto Arte, mas vou referir outros três exemplos já circulantes e reconhecidos.

O primeiro é o livro Enfrefalas, de Glória Ferreira, compilação de 13 entrevistas realizadas pela autora em diferentes momentos de sua trajetória intelectual, entre os anos 1980 e os 2000. Na introdução, ela revisa seu interesse por esse tipo de diálogo desde seu retorno ao Brasil, após longo período de exílio, e reafirma sua convicção de que a entrevista como gênero de texto "[...] assegura, no universo da arte, uma fala do artista não subordinada a julgamento, à avaliação crítica, inscrevendo-se, assim, no amplo movimento de tomada da palavra pelos artistas." ${ }^{22} \mathrm{Na}$ entrevista com Helena Trindade, curiosamente, as duas comentam o fato de ter sido a artista quem propôs à outra o formato de uma entrevista. Observa Helena: "A entrevista, quando bem conduzida, traz muita coisa que, se não fosse aquela oportunidade de a pessoa falar, não aconteceria. A fala se precipita à certeza. A escrita é uma coisa atrás da outra, tem muita edição, vai e volta."53

Segundo exemplo é o livro Arquivo contemporâneo, de Felipe Scovino, antologia de 13 entrevistas recentes, realizadas pelo pesquisador e crítico de arte entre 2006 e 2009 . No texto de abertura, ele faz uma comparação similar à de Glória Ferreira: "Não proponho nada mais do que retirar a fala (em demasia) em terceira pessoa (do crítico), e inserir a escrita ou o depoimento do artista." ${ }^{54}$ Adiante, no mesmo texto, Scovino especifica: "Organizando um livro de entrevistas, não quero afirmar que a crítica está em crise [...] ou [que] a palavra do artista é a única verdade sobre sua obra." ${ }^{55}$ Ao final do prefácio, sublinha o autor:

Essa reunião de textos aponta que a função de artista se converge para o lugar do crítico de arte, não no sentido de anular a sua função, mas de completar esse circuito crítico de pensamento. 0 artista não é apenas o sujeito que cria o objeto de arte, mas também reflete e pondera sobre esse processo e o seu lugar no circuito de artes, estabelecendo um discurso crítico sobre as transformações das práticas artísticas e do contemporâneo. ${ }^{56}$

A terceira referência corresponde ao livro No calor da hora - Dossiê jovens artistas paulistas (década de 1980). O volume reúne, passados 25 anos, 28 entrevistas realizadas por Tadeu Chiarelli entre 1986 e 1987, aos tempos em que ele atuava como pesquisador no Centro Cultural São Paulo. Na abertura, Tadeu esmiúça os critérios para a escolha dos artistas e estima que a leitura conjunta dos depoimentos poderá compor "[...] um painel do meio artístico paulistano, a partir de pontos de vista que nem sempre são levados em consideração."57 
Os três autores declaram, de diferentes maneiras, com distintas intensidades, a pretensão de oferecer ao público falas menos usuais, mas críticas, e, acima de tudo, livres de maiores interferências, a não ser aquelas do próprio diálogo entre entrevistados e entrevistadores.

Já foi dito aqui mesmo, neste artigo, que há uma proliferação de entrevistas com artistas. No Brasil, são muitas as publicações que se dedicaram a reproduzir essas sequências de perguntas-e-respostas. Algumas chegaram a se tornar referenciais: as de Lisette Lagnado com Iberê Camargo e Leonilson, a de Angélica de Moraes com Regina Silveira, a de Gerardo Mosquera com Cildo Meireles, as de Glória Ferreira com Nélson Félix. O que chama atenção, nos casos dessas compilações assinadas por Ferreira, Scovino e Chiarelli, é a opção pelo formato de antologia, que sublinha a potência da entrevista como gênero textual independente. Não se trata mais, em nenhum dos casos, de um livro monográfico sobre um artista, em que a entrevista é, em geral, um texto entre outros, embora às vezes seja o mais importante. A condição de antologia faz desses três livros, de fato, livros de entrevistas. Haveria que ressaltar também o estatuto acadêmico-científico de seus autores. Embora Ferreira, Scovino e Chiarelli tenham reconhecida experiência como críticos e curadores, são amplamente reconhecidos como professores-pesquisadores, com significativa atuação no meio universitário brasileiro, na área de Artes Visuais, Crítica de Arte e História da Arte. ${ }^{58}$

Daí a importância de se problematizar uma questão de natureza formal que acompanha as entrevistas publicadas nesses três livros: as conversações assumem um formato próprio do Jornalismo, o chamado pingue-pongue, ou mais intimamente pingue: perguntas e respostas transcritas uma após a outra, compondo um diálogo para ser lido. Não há, certamente, nenhum drama nessa escolha, mas o gosto por esse modelo deveria estimular algum questionamento: no que implica essa opção acadêmico-cientifica? Vamos levar ou não em conta que esse padrão provém da prática jornalística? Paradigmas emblemáticos do pingue-pongue jornalístico também vão nortear os pingues da academia? Abraçaremos o apreço pelo mais espetacular ${ }^{59}$, pelo sensacional, pela edição que melhora o que foi dito, que elimina redundâncias e cacoetes típicos da expressão oral, que altera a ordem das questões e que torna o texto tão diferente das entrevistas que entram como anexos e apêndices em teses e dissertações? Ou não estaremos dispostos a essas concessões? Se as fizermos, em nome da clareza, da elegância, da maior abrangência, da maior atratividade, da mais ampla autonomia da entrevista como texto, vamos considerar isso se porventura viermos a analisar o material?

Não estou defendendo, aqui, que se evite o formato dos pingues em textos não-jornalísticos. Ao contrário, sou, a princípio, simpático a eles, apenas advirto que isso deveria ser melhor observado e debatido - problematizado.
58. Glória Ferreira é doutora em História da Arte pela Universidade de Paris I, atualmente professora colaboradora do Pós-Graduação em Artes Visuais da Universidade Federal do Rio de Janeiro. Felipe Scovino tem doutorado em Artes Visuais pela UFRJ, hoje é professor naquela instituição e coordena o Pós-Graduação em AV. Tadeu Chiarelli é doutor em Artes Visuais pela Universidade de São Paulo, e professor titular daquela escola.

59. A esse respeito, ver Mucchielli: "A entrevista jornalística é um espetáculo, e o tema posto ou proposto é escolhido em função do público". In: MUCCHIELLI, Roger. A entrevista não diretiva. São Paulo: Martins Fontes, 1995, p.12. 
60. Relatório Capes de Avaliação Quadrienal 2013-2016 I Quadrienal 2017. Coordenação de Aperfeiçoamento de Pessoal de Nível Superior. Brasília, set. 2017. Disponível em https://docs.google. com/viewer? $a=v \& p i d=s i t e s \& s r c i d=$ Y2FwZXMuZ292LmJyfGF2YWxp YWNhby1xdWFkcmllbmFsfGd4Om ZiNWQOYjdIYWQyNzViZ Acessado em 25 set. 2017.
Recordo que um dos artistas entrevistados para minha pesquisa de Mestrado, ao ler o trabalho já pronto, notou que eu havia perdido a oportunidade de inserir as entrevistas transcritas no corpo mesmo da dissertação. Elas eram exaustivamente citadas e dissecadas ao longo de todo o texto, mas só nos anexos apareciam integralmente no formato pingue-pongue. Recentemente, uma amiga próxima, em sua pesquisa de doutorado, assumiu essa ousadia que me faltara, alternando os pingues com os capítulos de sua autoria exclusiva. A banca de avaliação, quase unanimemente, reclamou desse lampejo.

Não deixa de ser estranho que o formato, malgrado seu sucesso, malgrado esteja previsto inclusive em revistas acadêmico-científicas, seja em seções fixas ou em aparições eventuais, não receba a mesma pontuação nas avaliações da Capes. No recente relatório quadrienal da instituição, reafirma-se que, nas publicações dos Programas de Pós-Graduação, "[...] resenhas e entrevistas podem ser publicados, mas não são considerados como artigos originais." ${ }^{60}$ Mantido esse parâmetro, em uma próxima avaliação, o presente artigo vai contar menos pontos que a entrevista que eu próprio fiz com Maria Helena Bernardes para esta mesma edição da Porto Arte. 


\section{REFERÊNCIAS}

ALBERRO, Alexander; BUCHMANN, Sabeth (orgs.). Art after conceptual art. Cambridge / Londres / Viena: The MIT Press / Generali Foundation, 2006.

AMADO, Janaína; FERREIRA, Marieta de Moraes Ferreira (orgs.). Usos $\&$ abusos da História Oral. Rio de Janeiro: Fundação Getúlio Vargas, 1996.

ASSIS BRASIL, Luiz Antonio de (coord.); DOVAL, Camila Canali; SILVA, Camila Gonzatto da; SILVA, Gabriela (orgs.). A escrita criativa - Pensar e escrever literatura. Porto Alegre: Edipucrs, 2012.

BASBAUM, Ricardo. Além da pureza visual. Porto Alegre: Zouk, 2007. BLANCHET, Alain; GOTMANN, Anne. L'enquête et ses méthodes: l'entretien. Paris: Nathan, 1992.

BORGES, Jorge Luis; FERRARI, Osvaldo. En dialogo I. Buenos Aires: Sudamericana, 1998.

BOURGEOIS, Louise. Destruição do pai / Reconstrução do pai. São Paulo, Cosac Naify, 2000.

BUENO, Cleuza Maria de Oliveira. Entre-vista: espaço de construção subjetiva. Porto Alegre: Edipucrs, 2002.

CHAUVEAU, Agnès; TETART, Phillipe (orgs.) Questões para a História do Presente. Bauru: Edusc, 1999.

CHIARELLI, Tadeu. No calor da hora - Dossiê jovens artistas paulistanos (década de 1980). Belo Horizonte: C/Arte, 2011.

Cultura. Zero Hora. Porto Alegre, 4 fev. 2006.

CRIPA, Marcos (org.). Entrevista e ética: uma introdução. São Paulo: Edusc, 1998.

DETTERER, Gabriele (org.). Art recollection - Artists' interviews and statements in the Ninethies. Ravena: Danilo Montanari / Exit / Zona Archives Editori, 1997.

ECO, Umberto. Apostillas a El nombre de la rosa. Buenos Aires: Lumen / Flor, 1987.

FERREIRA, Glória. Entrefalas. Porto Alegre: Zouk, 2011. ; FÉLIX, Nelson. Trilogias - Conversas entre Nelson Félix e Glória Ferreira. Rio de Janeiro: Pinakotheke, 2005. ; COTRIM, Cecilia (orgs.). Clement Greenberg e 0 debate crítico. Rio de Janeiro: Jorge Zahar Editor, 1997.

Inf. \& Soc. João Pessoa, v. 24, n. 1, p.13-18, jan. / abr. 2014. KIEFER, Luísa Martins Waetge. Jovem artista: a construção de um duplo mito. Programa de Pós-Graduação em Artes Visuais. Universidade Federal do Rio Grande do Sul. Dissertação (Mestrado). Porto Alegre, 2013.

KUH, Katharine. Diálogo com a arte moderna. Rio de Janeiro: Lidador, 1965.

LICHTENSTEIN, Jacqueline (org.). A pintura: textos essenciais. Vol. 7: O paralelo das artes. São Paulo: Editora 34, 2005. LINS, Consuelo. $O$ documentário de Eduardo Coutinho. Rio de
Janeiro: Jorge Zahar, 2004.

MEHY, José Carlos Sebe Bom. Manual de História Oral. São Paulo: Loyola, 2002.

MORIN, Edgar. Cultura de massa no século XX: o espírito do tempo. Rio de Janeiro: Forense Universitária, 1990.

MUCCHIELLI, Roger. A entrevista não diretiva. São Paulo: Martins Fontes, 1995.

OBRIST, Hans Ulrich. Arte agora!: em cinco entrevistas. São Paulo: Alameda, 2006.

PONGE, Francis. Métodos. Rio de Janeiro: Imago, 1997.

Revista do Programa de Pós-Graduados em História e do Departamento de História - PUC SP. Projeto História, São Paulo, n. 14, fev. 1997.

Revista Educação. Porto Alegre, v. 22, n. 37.

SANTHIAGO, Ricardo. História Oral e as artes: percursos, possibilidades e desafios. In: História Oral, v. 16, n. 1, jan./ jun. 2013.

(org.). História oral e arte: narração e criatividade. São Paulo: Letra e Voz, 2016.

SCOVINO, Felipe. Arquivo contemporâneo. Rio de Janeiro: 7 Letras, 2009.

SHERWOOD, Hugh C. A entrevista jornalística. São Paulo: Mosaico, 1981.

STILES, Kristine; SELZ, Peter (org.). Theories and documents of contemporary art: a sourcebook of artist's writings. Berkley: University of California Press, 1996.

TOMKINS, Calvin. Duchamp: uma biografia. São Paulo: Cosac Naify, 2004.

VERAS, Eduardo. Entre ver e enunciar - O uso da entrevista em estudos sobre o processo de criação artística. Programa de Pós-Graduação em Artes Visuais. Universidade Federal do Rio Grande do Sul. Dissertação (Mestrado). Porto Alegre, 2006.

\section{Eduardo Veras}

Crítico e historiador da arte, atuando também como curador independente. Professor Adjunto do Instituto de Artes da UFRGS, ministra aulas e orienta pesquisas no Programa de Pós-Graduação em Artes Visuais e no Bacharelado em História da Arte. Dedica-se aos seguintes temas: historiografia e crítica de arte na contemporaneidade, relações entre palavra e imagem, artistas em deslocamento e entrevistas com artistas. É membro do Comitê Brasileiro de História da Arte e do Conselho Deliberativo da Fundação Vera Chaves Barcellos.

(*) Texto submetido em novembro de 2017. 